\title{
A Conversation with Ray Ozzie
}

$\mathrm{T}$ here are not many names bigger than Ray Ozzie's in computer programming. An industry visionary and pioneer in computer-supported cooperative work, he began his career as an electrical engineer but fairly quickly got into computer science and programming. He is the creator of IBM's Lotus Notes and is now chief technical officer of Microsoft, reporting to chief software architect Bill Gates. Recently, Ozzie's role as chief technical officer expanded as he assumed responsibility for the company's software-based services strategy across its three major divisions.

Ozzie, who turns 50 this month, says he doesn't code much these days, but still gets very deeply into the architecture of the projects that he works on. "What really intrigues me are the social and organizational aspects of what works and what doesn't," he says, "and how to weave the technology together into a form that accomplishes what people need to accomplish while giving organizations what they need out of those interactions."

Ozzie is the founder of Groove Networks Inc., a leading provider of collaboration software for the virtual office, which Microsoft acquired in April 2005. Before founding Groove Networks in 1997, Ozzie was the founder and president of Iris Associates, where he led the initial development of Lotus Notes. Before Iris, Ozzie was instrumental in the development of Lotus Symphony and Software Arts Inc.'s TK!Solver and VisiCalc, and was involved in early distributed operating systems development at Data General Corp.

Ozzie earned a bachelor's degree in computer science at the University of Illinois at Urbana-Champaign. He is honored as one of seven Windows Pioneers by Microsoft, and was inducted into the Computer Museum Industry Hall of Fame as well as the InfoWorld Hall of Fame. In November 2000, he received the Institute for Electrical and Electronics Engineers (IEEE) Computer Society's W. Wallace McDowell Award.

He is interviewed by Queue editorial board member Wendy Kellogg, who heads the Social Computing Group at IBM's T.J. Watson Research Center. She has been working in the areas of human-computer interaction and collaborative technology for the past two decades. Her

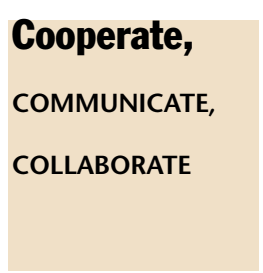

current work involves designing and studying systems for supporting computer-mediated communication (CMC) in groups and organizations. She holds a Ph.D. in cognitive psychology from the University of Oregon. She was elected ACM Fellow in 2002.

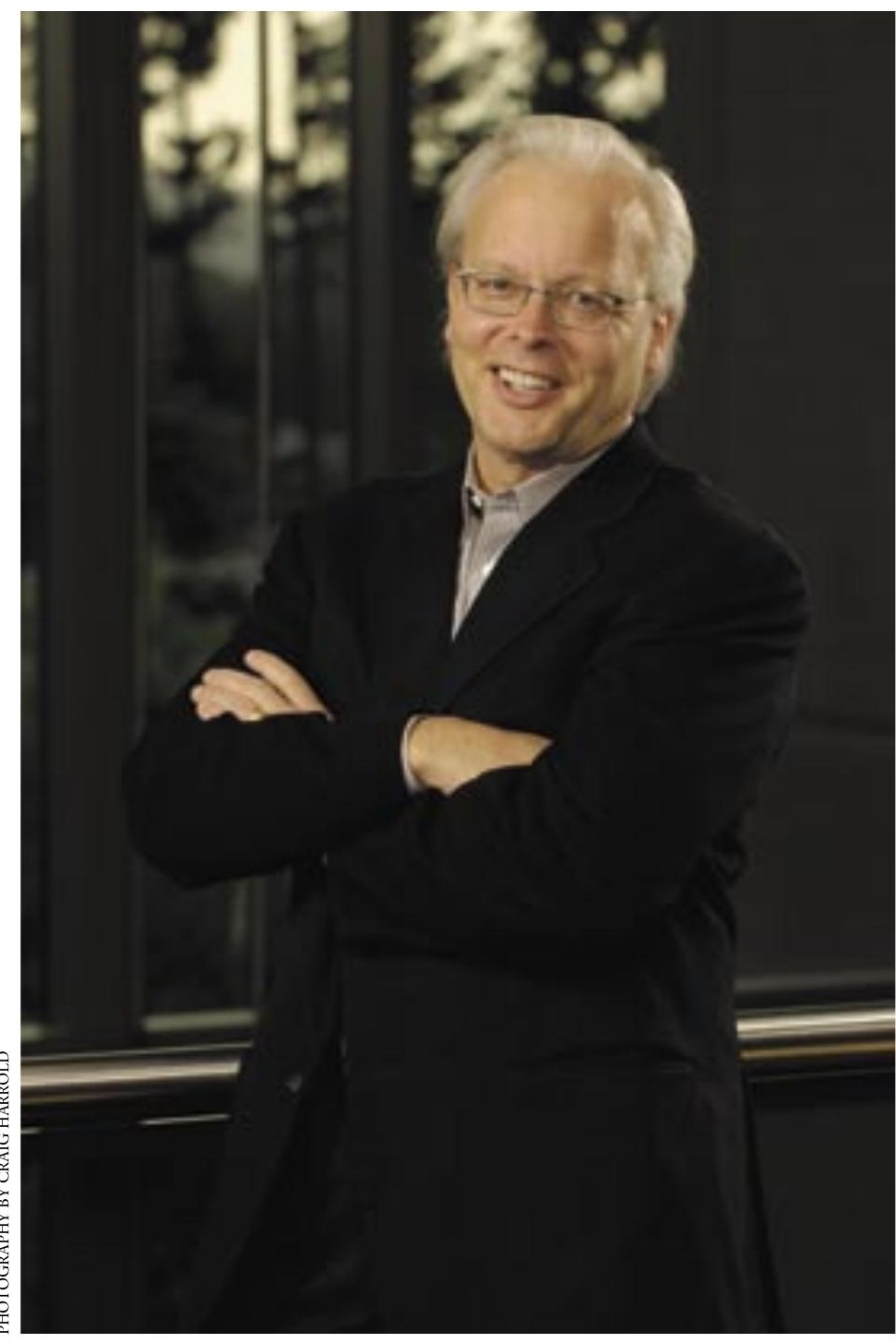

rants: feedback@acmqueue.com 


\section{interview}

WENDY KELLOGG Bill Gates once called you one of the top five programmers in the universe. Are you or were you one of the top?

RAY OZZIE A most overplayed quote. I met him and Steve Ballmer in the early 1980s when I was working at Software Arts on a product from long ago called VisiCalc. Over the years, I think they liked the fact that the systems I've built, both in Notes and in Groove, were of fairly substantial complexity and focused on solving real pain for customers. My teams and I had a way of weaving together that complexity in a way that didn't really interfere with the user's ability to use it or the administrator's ability to manage it.

WK That's kind of the Holy Grail of integrating technology, isn't it?

RO Well, that's what we seek to do. I think in the realm of collaborative software, it's probably even more critical because we're not just teaching one user how to use the system. For it to be effective, you need to draw people into it and get them to actively use it, and that means that the number of points of failure is much greater.

WK How important is collaboration to organizations today? Do you think we're in the midst of a resurgence of collaboration?

RO Well, this is my passion, but I do believe collaboration is tremendously important. In most major enterprises, there are formalized business processes that people understand. You have some companies that are very, very into the structured process aspects of their business and the process optimization, whether it's Wal-Mart with the logistics or Dell, which is very focused on business processes.

On the other side of the spectrum are what I would refer to as the business practices-the more unstructured things that people do at the edge of the organization, and that's really project-centric work. It's really important for companies to understand how they focus and optimize their business processes and how they support their people in terms of their day-to-day practices.

Certain types of corporations, such as professional services organizations, are much more on the business practice side. They have to focus on enabling people to do their jobs and on the knowledge aspects of their businesses. There are manufacturing companies that are on the other side of the spectrum, but I think to some degree, there's an element of business process and business practice within every company. How technology can be used to augment that human interaction is what turns me on.

WK Business visionaries Tom Malone and Peter Drucker postulate that more and more businesses are going to become decentralized and move from the command-andcontrol model to cultivate-and-coordinate over the next few decades. There are a lot of skeptics about this in the business world, but if it's going to happen, what does that mean for collaborative technology, or this idea of "coopetition"?

RO When I was at Lotus in the early '90s, companies were a lot more vertically integrated than they are right now.

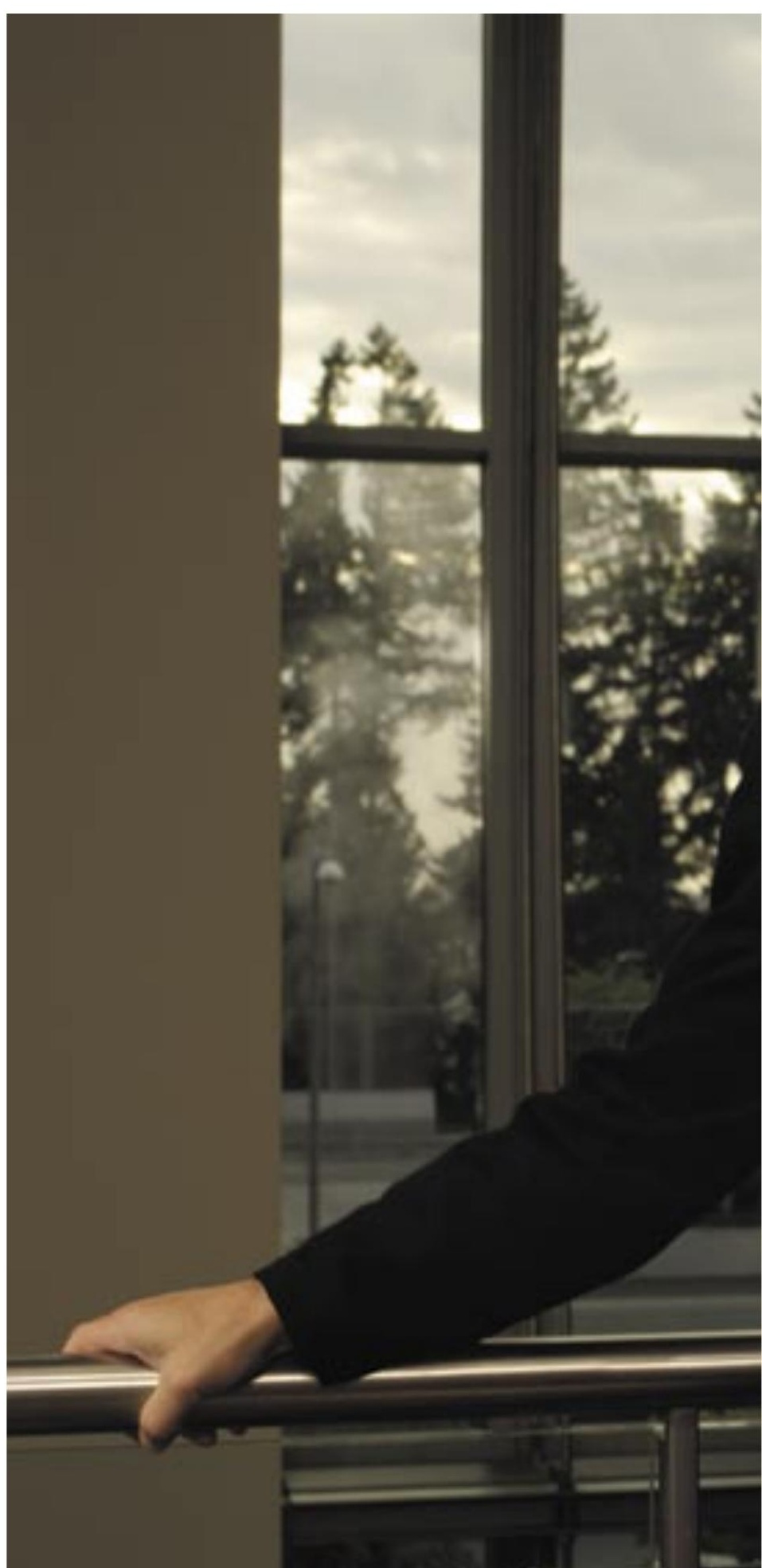


At that time, people were attempting to use fairly nascent technology to break down the walls within the organization, meaning they were trying to get different departments within an organization to work together. They were trying to flatten organizations internally and get people to work together across stovepipes, within organizations, just to make processes operate more smoothly.

Fast-forward to today, and you find that we all take that for granted. Most companies nowadays use a mix of technologies: certainly e-mail and, in various flavors, some other types of collaborative technology internally. But now the business imperative is much different. Essentially, many, many companies have to integrate outside business partners into their core practices. Companies are, for better or worse, needing to distribute their operations geographically, in many cases into Asia and other places where people are operating on the same project but in different time zones.

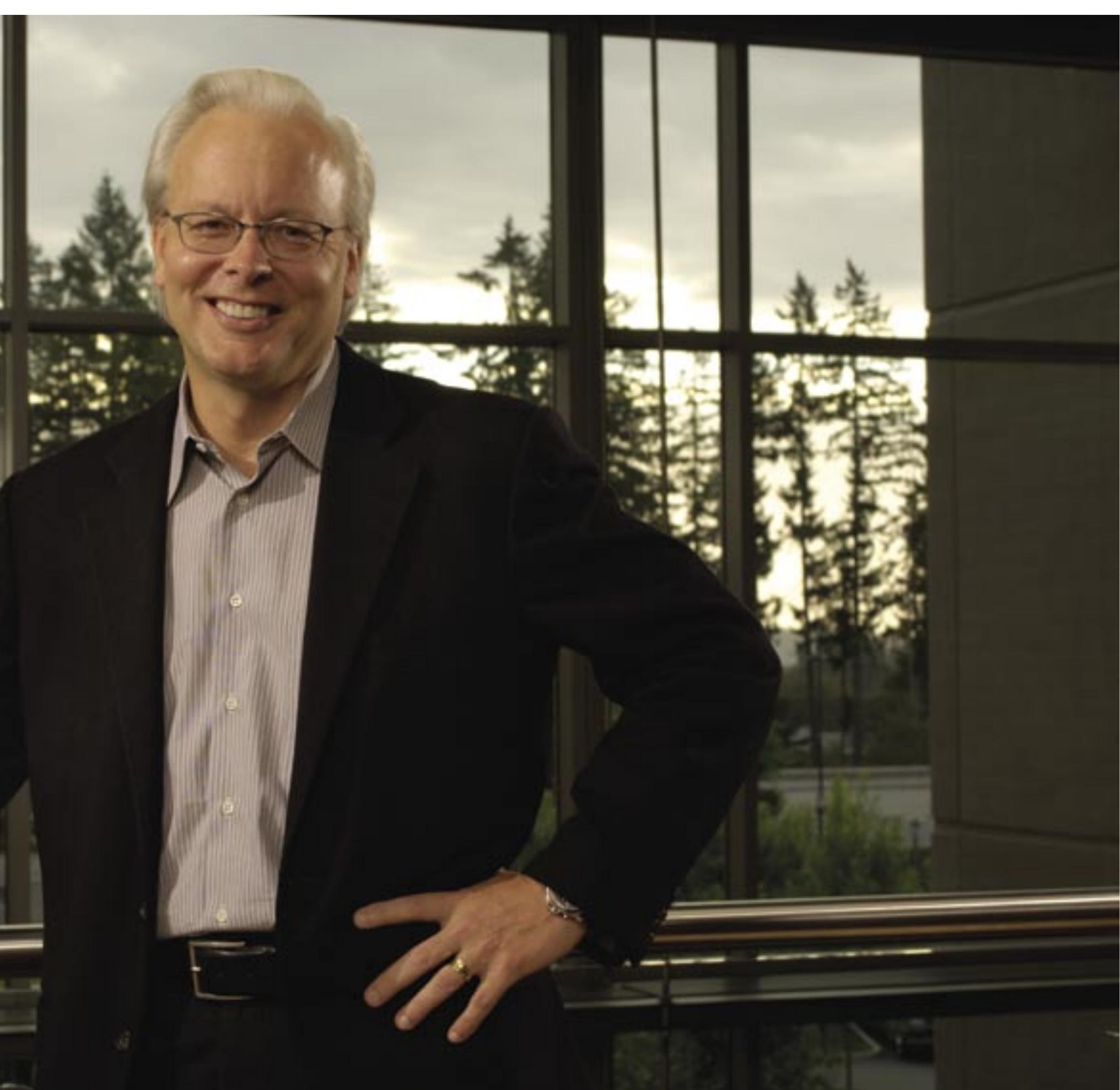


Essentially, the walls are coming down in so many different ways, and organizations have to figure out how to effectively do what they need to do in a very, very decentralized manner.

Tom Malone has been saying this, and Peter Drucker's idea of "The Next Society" is that in the future we're going more or less from corporation to confederation where many, many small firms united by a common strategy and common economic goals will get together to produce a product or a service, and then reband with a different set to produce a different product or service. We're seeing the leading edges of this, and again I think that technology plays a tremendous role in helping these teams virtually assemble, get their jobs done very effectively, and disassemble as the business requires.

WK Do you have any ideas about what technology can do or what particular technologies can help support collaboration that may involve cooperation and competitive or even adversarial aspects?

RO The first thing to realize, whether these companies are cooperating or competing, is that the core tenet is different from the tenet upon which we built systems in the past. The tenet now is that you can't control the IT infrastructure of your business partners. Many of the systems in the past produced by all of the major playersMicrosoft, IBM, Oracle-assumed that the data center and the enterprise were the root of management and deployment of the applications and the directory. We built applications and the security model on those applications around that assumption.

Now, if you need to collaborate with people within other corporations and you can't dictate their IT choices, it really causes you to step back and say, "Wait, what technology can I or should I use to get these people to work together?" The default technology for collaboration is e-mail because it seamlessly crosses those enterprise boundaries, but e-mail is 30-some years old and has been stressed well beyond its original design center. That's why I believe a number of customers are looking for other types of technologies to support those cross-boundary interactions, and that's why you see products such as Groove, products that are appearing out on the Internet, that are more or less boundary-spanning, whether they be wikis or blogs or Skype or a number of interesting technologies like that.

WK We could say it's an exciting time, with all the kinds of technologies that are emerging: the ones you mentioned, VoIP, RSS, this idea of social tagging, folksonomies, things like del.icio.us and Flickr, and even broadcast messaging. How quickly do you think these technologies are going to penetrate mainstream business, if they do at all? If we were all to go on holiday for the next decade and then come back to work, would we recognize the workplace, or would we already be at work and not have to come back?

RO Sadly, I think enterprises have a lot of issues going on inside them that make it very difficult to embrace some of these innovations. Frankly, the path that we're on leads one to believe that a lot of the benefits of these innovations are accruing to small businesses and individuals much more readily than enterprises. The reason: Enterprises are really different from the public Internet in that they have fairly substantial compliance issues. They have control hierarchies related to technology acquisition and enablement of end users. They mandate the use of certain technologies and mandate that others not be used. They control the upgrade tempo. I've never seen the technology environment as divergent as it is right now between what's going on outside enterprises and what's going on inside enterprises.

There are other issues as well. For example, the search technologies that work on the outside of the enterprise are completely different from the ones that work on the inside because, at least in today's Internet, people like to make things public. They tag things, they write things on blogs, and post pictures to Flickr, whereas within enterprises, there are many well-entrenched things related to hoarding, hiding, and securing information that results in information being siloed. So some of the core ways that relevance is determined on the open Internet, such as references, don't work on the inside-you don't have people writing in a public forum within a corporate network talking about and pointing at other things, because everything is in these little compartments.

A lot of the social software that is now appearing on the public Internet, which is a bit like a petri dish, really must be thought of from the perspective of how it would play inside an enterprise. How can some of that software be adapted for use in the enterprise? It's difficult for me to conceive of how some of that petri-dish software will become accepted inside the enterprise because of some of the overwhelming compliance and security issues that exist there.

WK Certain things, such as e-mail, started inside companies. That is, e-mail was only inside the company and now it's pretty universally available outside of enterprise boundaries. There's some evidence that things like wikis and blogs are happening inside enterprises. So maybe there's some hope.

RO Well, there is hope, but we have yet to see how 
they're going to be adapted. For example, e-mail within enterprises has some fairly different characteristics in some enterprises than in others. E-mail is owned by the corporation and has message-store limits and attachment limits. There are usage methodologies that differ from the outside.

In terms of wikis, for example, we've seen some fairly interesting early uses. I've also seen them shut down in two very specific cases where people really enjoyed the uncontrolled use, meaning they were beginning to build up a knowledge base. But the IT department was very worried in terms of whether this is a communication mechanism or a data mechanism. If it's a communication mechanism, how does that play into compliance with the Sarbanes-Oxley Act or CFR (Code of Federal Regulations) Part 11? All of these issues come up.

WK What should technologists within businesses be worried about or thinking about in the area of emergent collaboration technology? What technical challenges do they face? RO The first thing to recognize is that collaboration and communication technology is not a panacea. Many people, particularly in the early years when I first brought Notes to market, would have problems that they were trying to work out within their company, and they would deploy this collaboration software thinking it would solve the problem. In fact, many times what they were really trying to do was institute business process or culture change at the same time the technology was deployed. When the initiative failed because of inadequate recognition that they were trying to change the process, or the culture, they would blame the technology.

Technology can assist the change, but it can't make it happen on its own. People really have to understand what the role of technology and the role of leadership are when it comes to effecting change within corporations.

The second thing is to understand the differing roles of IT and the line of business and the individual, because they're very, very different. IT is really an enabler that provides tools to the organization. IT should be very conscientious about providing mechanisms for knowledge repositories and document libraries, and should be deal-

ing with compliance issues and so on.

But IT really needs to leave it to the line of business to understand what the key collaborative processes are. The line of business really has to understand the role of structured processes versus ad hoc projects, and it has to assist IT in defining what tools are best to enable its structured processes and ad hoc processes. The line of business must understand the skills of the people and how best to match the tools with those skills.

From the perspective of an individual, changing someone's behavior is really difficult. Organizations have to recognize what works with people and what doesn't.

People generally like to assemble dynamically, deciding how to form their projects and what tools they need to get a project done. They like ad hoc things that are in their control; however, organizations need to weave the results of those projects into processes, and people need to be handed tools and trained to respect the organization's process needs at the same time that they're being empowered with these tools.

For example, if somebody did all of his or her work totally in an ad hoc, unstructured manner, there would be no artifacts that benefited the organization.

At the other end of the spectrum, if a company is so focused on the artifacts and it forces all work to be done through a browser, for example, then it can fail because it 
doesn't match the way that people work. Sales force automation is a really good case in point where the pendulum swung toward Web-based systems a number of years ago and every major vendor of sales force automation had to make a browser-based version of its products. But that's not the way salespeople work. Salespeople are on the road all the time and they use the phone a lot. If you don't design the tools to match the way people actually work, you end up with shelfware.

WK Large-scale collaboration is one of the most interesting emerging kinds of technologies. Broadcast messaging, the ability to reach out across your enterprise and ask questions or interrupt people, is probably just the tip of the iceberg here. I'm reading The Wisdom of Crowds (Doubleday, 2004) by James Surowiecki, who talks about the long-recognized phenomenon that if you ask a lot of people a question where there's a lot of uncertainty and then look at the mean tendency of the answer, it tends to be correct.

It's like the audience lifeline in "Who Wants to Be a Millionaire?" Ask a question of the audience and let them vote on the answer. So the question here is, can technology help a large collective of people cooperate with each other, maybe pool their abilities and knowledge, to make more intelligent decisions? And, really, would we want it to if it could?

RO It's an intriguing question. What we already know is that MSN Search and Google and others like that have proven that the long tail of the Internet has answers to many questions. Many of us pose questions in the form of queries to these engines and we get back answers that you would never expect given the size of the corpus out there.

There have been several attempts to build systems where you pay people to answer interesting questions. I don't think that they have done what you're suggesting in terms of collecting the answer from a number of people and taking the mean. I haven't seen that kind of thing, at least on the public Internet, succeed anywhere near the degree of the pure information-based one.

WK The data-mining approach?

RO Yes. I'm still more focused on the data-mining approach, particularly within enterprises, because I think one of the big promises of all of this technology is to make it easy for people to leave trails of artifacts that can be used later when you don't really expect it. Groove Networks did quite a bit of work with the government, particularly in the realm of post-9/11 information-shar- ing across agencies. Again, the problem is that people hold information close to the vest. The promise is that we can develop systems where people create artifacts and query engines that can get relevant answers to questions at a time disconnected from when the information was produced. I think there's a lot of promise in this area. I just don't know what form it's going to take.

WK There seems to be an alphabet soup of technologies, such as Ajax and RSS, for developers who brew together these social software applications. Do you have any advice for a newcomer on how to get started in writing an application with this stuff? Is there a place to look for inspiration or example code?

RO I don't want to turn this into a commercial, but a lot of Microsoft's focus is on developers. On the Internet, people can download many libraries of code, related both to Microsoft technologies and to other technologies. Surely, the purpose of what we do is to try to make things very easy for developers to build solutions very, very rapidly.

The things that you mentioned are in different parts of the stack. Ajax is a very interesting and robust way of improving the user experience within the browser. It used to be called DHTML (dynamic HTML)-based Web programming, and now it's got a tag called Ajax. There are a number of toolkits out there, some freely available for download. Some are available in upcoming versions of Microsoft's Visual Studio .NET.

Going back to the idea of making data available to the public and making systems that are collaborative, bringing together many people's data, XML is a very powerful concept. That's what a number of the search engines and systems such as Technorati and bloglines are based on. They aggregate multiple people's work.

WK Tim O'Reilly, founder of O'Reilly Media, coined the phrase "the architecture of participation," meaning a lot of amateur and casual programmers piling on and building interesting things off the snippets of codes and applications that are out there. What are the open APIs and standards that a developer should keep track of in collaborative applications? Do you have any tips on how to craft an API amenable to this kind of open participation, to put things out there that can get picked up and reused?

RO Dan Bricklin also has a great phrase, "cornucopia of the commons," that refers to the same thing-about how the commons becomes more valuable than the different pieces that are contributed. I think it's a very important concept and spans far beyond collaborative software. It's really what is defining this next wave of the Internet. 
I believe that the platform of the Internet really is the data, and by putting data out there that is re-mixable into different types of applications, we can get interesting, unanticipated results. The most fundamental standards around that start with XML, but it really revolves around what some people call microformats, small formats that are easily understood and generated by a broad variety of applications, such as iCal, hCal, and vCard, and then encapsulating them in RSS.

RSS is an extremely important standard. It's the HTML of the next generation of the Web, or some people might refer to it as the Unix pipe of the Internet. It's a way of channeling data from one application to another in very interesting and robust fashion. Again, I think it's important as a technique far beyond just collaborative software.

WK What do you see as the major technical challenges in creating collaboration technologies now? Is it offline use, or longstanding transactions, or conflict detection and resolution, or what?

RO Fundamentally, what's happening on the Internet in highest volume are the things that are easy to do by building a quick application server. There are so many technologies out there right now that you can just download and whip up a very simple appserver, and that makes it very easy for people to experiment.

There are some challenges related to authentication of users in the Internet environment. Trust is a huge thing in effective collaboration, and making sure that you're setting up trust in your environment is fairly important. As you said, offline is extremely critical. It's very difficult to do right, but as was evident in Louisiana after Hurricane Katrina-when emergency responders are trying to get together and collaborate on bringing aid to people, when the infrastructure is rough and sometimes you have Internet connectivity and sometimes you don't-using products where offline support works is absolutely critical. That was fundamental to both the designs of Notes and Groove. Given how mobile we are today, knowing that we work from home, the office, the airport lounge, a customer's conference room, or a local Starbucks, factoring the ability to work on- and offline into a collaboration solution is essential. You can't always assume that the people you're working with will have an Internet connection. We've seen it with Katrina. We saw it with 9/11. We'll see it again with the next crisis.

WK What are you most excited about at the moment? If you could wave your magic wand and cause one change to people, or in organizational attitudes and business management, or in the state of the technology, what would you try to change?

RO When it comes to the public, if I could wish for something, it would be that all citizens get broadband and have access to wireless infrastructure, because I think both of those in different ways really change the way people will interact with other people, their devices, and their software. Unfortunately, I think we're heading down a path where the fortunate have fiber, the unfortunate have dial-up, and the middle of the bell curve have cablemodem access. This is not an optimum situation for our society.

In the enterprise, I think if I could wave my wand, there would be some solution that would correct the increasing divide between enterprises and home use. As a software maker, I'm extremely frustrated by the fact that when you look at the market, both small businesses and consumers go to Dell.com, order their computers, and get the latest and greatest version of Microsoft Office and the latest operating system. Then they download all this really neat, new stuff off the Internet. These individuals and smaller businesses are really benefiting from that.

Enterprises, on the other hand, are getting increasingly locked down and conservative because of compliance and CYA issues. I'm worried about that. And I believe enter- 


\section{interview}

prises should be concerned about this because it's impacting their ability to be nimble and adaptive in today's global market.

WK That heads us toward an interesting impasse where people's experience outside the workplace is going to exceed their [technology] experiences inside.

RO I've already seen people bringing their home laptops into work to do their jobs. People are using a product called the Junxion Box, which creates a bridge from high-speed commercial $3 \mathrm{G}$ data services to $\mathrm{Wi}-\mathrm{Fi}$, to create their own non-IT-managed wireless clouds within corporate boundaries so they can work in the office as they do at home.

I only see this bifurcation between the home and office experience becoming an increasing problem.

WK As you look back on your professional accomplishments in collaborative technology in the past few decades, can you tell us what it is that you're most proud of and what else you look forward to accomplishing? RO When I first started being excited about the use of technology to augment collaboration, this was very, very early and technology wasn't anywhere near as ubiquitous as it is now. I feel very fortunate to have been involved in helping create some of these systems with my teams. It's rewarding to know that in some cases we helped reshape the operations of some businesses and delivered real bottom-line value.

It's also really exciting when you know you've created opportunities for other individuals and entrepreneurs, or for individuals to have rewarding jobs within large companies related to the technologies you've produced.

I've been fortunate to have worked on technologies that have become ubiquitous, with more than 100 million users. It's gratifying when I go to conferences and somebody comes up and says, "For the past 10 years I've had a business based on your product. We started with nothing. Now I've got 30 employees and we do this and this and this, and I just wanted to thank you."

That's what makes it all worthwhile. I really enjoy building technology that is leveraged by others for their own business value or for their own careers or for their own business opportunities. That's what's really exciting, and I look forward to continuing to do that. $Q$

\section{LOVE IT, HATE IT? LET US KNOW}

feedback@acmqueue.com or www.acmqueue.com/forums

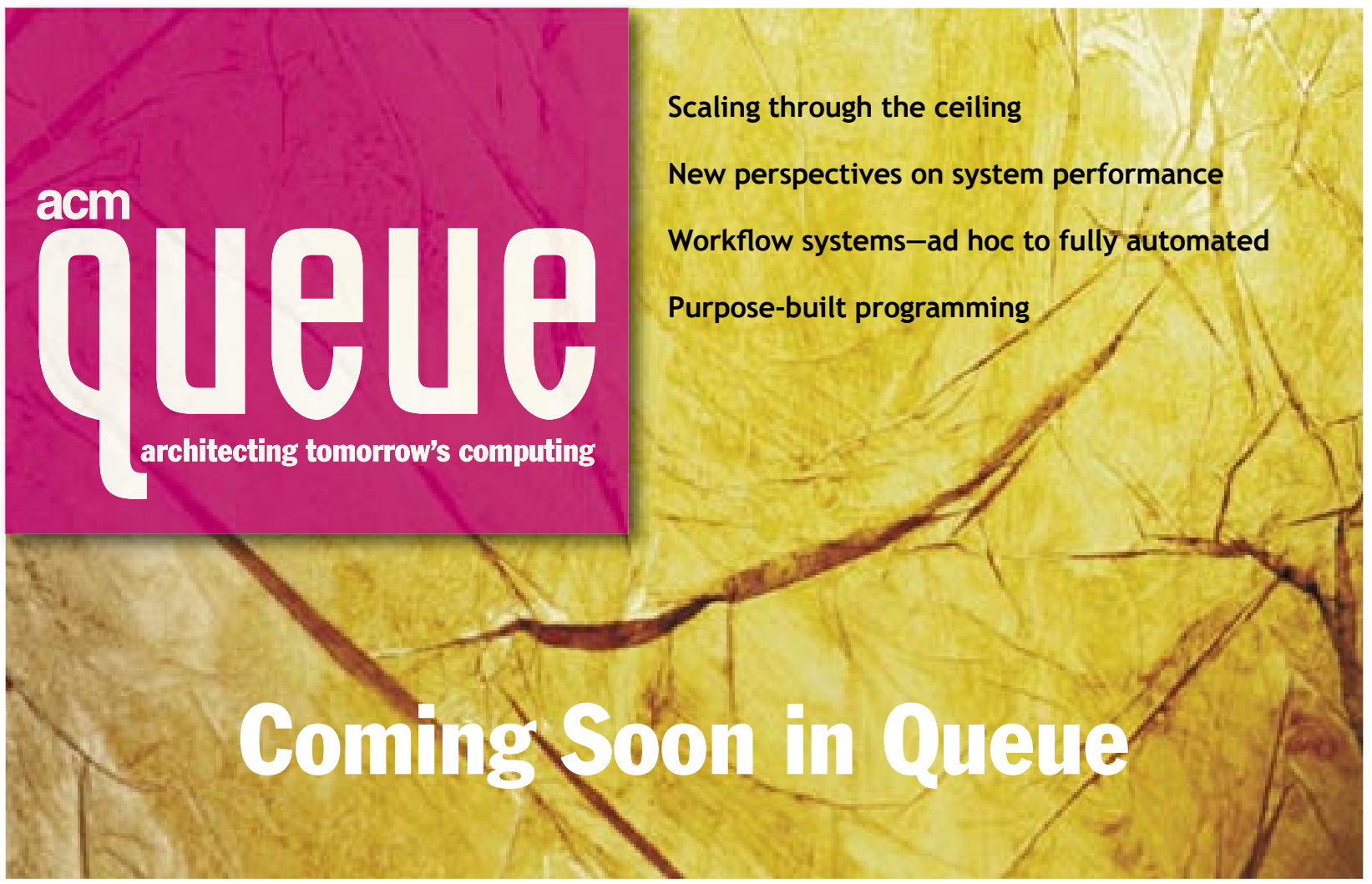

